ECOLOGICA, Vol. 28, No 104 (2021), 658-664

https://doi.org/10.18485/ecologica.2021.28.104.23

Originalni naučni rad

UDC: $655.3 .066 .12: 502](497.11)$

\title{
Analiza medijskih sadržaja o životnoj sredini u dnevnoj štampi u Republici Srbiji u vreme pandemije COVID-19
}

\section{Analysis of media coverage on the environment in daily newspapers in Republic of Serbia during the COVID-19 pandemy}

\author{
Milovan Vuković ${ }^{1 *}$, Aleksandra Vuković2 ${ }^{2}$ Nada Štrbac ${ }^{3}$, Danijela Voza ${ }^{4}$ \\ 1,3,4Univerzitet u Beogradu, Tehnički fakultet u Boru, Vojske Jugoslavije 12, 19210 Bor, Srbija / \\ University of Belgrade, Technical faculty in Bor, Vojske Jugoslavije 12, 19210 Bor, Serbia \\ ${ }^{2}$ Akademija tehničko-umetničkih strukovnih studija; Odsek: Visoka železnička škola, Z. Čelara 14, Beograd / \\ Academy of Technical and Artistic Vocational Studies; Department: Railway College, Z. Čelara 14, Belgrade \\ *Autor za prepisku / Corresponding author
}

Rad primljen / Received: 04.09.2021, Rad prihvaćen / Accepted: 09.11.2021.

Sažetak: Tokom protekle godinu dana, u vreme pandemije Kovid 19, zalaganja za zaštitu životne sredinne nisu iščezla. Poznata je činjenica da kominikacija predstavlja efektivno sredstvo za podsticanje javnosti da se uključi u različite prakse ekološkog menadžmenta. Štampa je, među ostalim komunikacionim sredstvima, značajan kanal za širenje informacija o životnoj sredini. Cilj ovog rada je da se istraži prisustvo sadržaja o živornoj sredini u uticajnim denvnim listovima u Srbiji (Politika, Danas, Večernje novosti i Kurir). U nastojanju da se obavi ovaj istraživački zadatak, primenjen je mešoviti metodološki pristup, korišćenjem i kvalitativnih i kvantitativnih metoda. Primarni podaci su sakupljeni metodom analize sadržaja. Dobijeni rezultati pokazuju da je štampa demonstrirala njenu moć širenja ideja i podizanja svesti svojih čitalaca o aktuelnim pitanjima zaštite životne sredine. Kroz uravnotežen i višedimenzionalan način, uz zauzimanje kritičkog odnosa prema slabostima postojećih mera i predlaganje mogućih rešenja. Načini predstavljanja ekoloških tema u ova četiri dnevna lista razlikuju se značajno; pre svega, u pogledu obima sadržaja, tematske raznovrsnosti, nivoa značajnosti i kritičkog sagledavanja vladinih napora u oblikovanju ekološke politike. Jasno je da se Politika, najstariji srpski dnevni list, izdvaja svojom dogoročnom posvećenošću ekološkoj problematici.

Ključne reči: ekološko obrazovanje, teme o životnoj sredini, analiza sadržaja, dnevna štampa, pandemija, Republika Srbija.

\begin{abstract}
In the last year, during the COVID-19 pandemy, a call for envronmental protection has not vanished. It is a wellknown fact that communication represents an effective tool for encouraging the public to engage in various practices of environmental management. Among different communication tools, the press seems to be an important channel for distributing information dealing with the environment. The objective of this study is to explore the news coverage of environmental issues in Serbian influential daily newspapers: Politika, Danas, Večernje novosti and Kurir. In order to carry out this research task, a mixed methodological approach was applied, by using both the qualitative and quantitavie methods. Primary data were gathered through content analysis. The obtained results show that press has demonstated its power to spread ideas and encourage readers' awareness of pressing issues. In the investigated period, press reflected the diversity of environmental issues objectively, honestly and from multi-faced approach, acting often as a critical channel - focusing on weaknesses and alternative solutions. The ways of representation of environmental issues in these three newspapers were different significantly in terms, first of all, extent of coverage, types of enviornmental issues, level of prominence, and critial view of goverments' efforts in environmental policy shaping. It is obvious that Politika, the oldest Serbian newspaper, stands out due to its long-lasting commitment to environmental issues.
\end{abstract}

Keywords: environmental education, environmental themes, content analysis, daily newspapers, pandemy, Republic of Serbia.

10rcid.org/0000-0003-1715-1078, e-mail:mvukovic@tfbor.bg.ac.rs

2orcid.org/0000-0003-4864-2080, e-mail:dr.milovanvukovic@yahoo.com.

${ }^{3}$ orcid.org/0000-0003-4836-1350, e-mail:nstrbac@tfbor.bg.ac.rs

${ }^{4}$ orcid.org/0000-0003-0895-731X, e-mail:dvoza@tfbor.bg.ac.rs 


\section{UVOD / INTRODUCTION}

Kada se u proleće 2020. godine globalna zdravstveno-ekonomska kriza prouzrokovana pandemijom Kovid-19 uveliko proširila u evropskim zemljama, uključujući i Srbiju (prvi slučaj zaraze registrovan 6 . marta u Novom Sadu), pojavila se bojazan da bi teme o životnoj sredini u najuticajnijim medijima mogle da budu slabije zastupljene kao i kvalitet njihove obrade; na primer, osetno smanjenje analitičkih tekstova. Strahovalo se takođe da bi u odsustvu široke javne debate, zbog nametnutih ograničenja svakovrsnih kontakata, rešavanje mnogih ekoloških pitanja moglo da izgubi na značaju u definisanju i sprovođenju javne politike u ovoj oblasti. Posebno se to odnosi na problem zagađenosti vazduha koji se decenijama nalazi na vrhu liste prioriteta za rešavanje ne samo u Srbiji već i u ostalim zemljama Zapadnog Balkana. Aktuelna zdravstveno-ekonomska kriza pokazuje, čini se, da različiti aspekti životne sredine ostaju, u većoj ili manjoj meri, u žiži interesovanja poslenika javne reči - naročito u najuticajnijim štampanim medijima (dnevnim novinama). Učestale poruke odaslate preko ovog vida ekološke komunikacije, što će kasnije biti ilustrovano odgovarajućim primerima, podstiču donosioce odluka da i u uslovima tzv. nove normalnosti pravovremeno reaguju u cilju rešavanja konkretnih problema.

$\mathrm{U}$ ovom radu su, na tragu uvodnih pretpostavki, izloženi i analizirani rezultati istraživanja ekološke komunikacije preko štampanih medija u vreme pandemije u Republici Srbiji. Osnovni ciljevi istraživanja se odnose na: (1) procenu značaja izveštavanja o životnoj sredini u uticajnijim dnevnim listovima u Srbiji (Politika, Danas, Večernje novosti i Kurir); (2) identifikovanje ekoloških tema koje su najčešće obrađivane; te (3) formulisanje mera koje bi omogućile bolji kvalitet izveštavanja javnosti o ekološkim temama. Krajnji cilj istraživanja je da se ispitaju činioci koji doprinose poboljšanju informisanja o životnoj sredini.

U nastavku rada su najpre izložene osnovne postavke koncepta ekološke komunikacije i primenjenog metodološkog pristupa, čija okosnica je metoda analize sadržaja, dok se preostali sadržaj rada odnosi na postavljene ciljeve istraživanja.

\section{TEORIJSKI OKVIR / THEORETICAL FRAMEWORK}

Ekološka komunikacija (EK) je proces prenosa informacija o životnoj sredini posredstvom različitih kanala. Ovaj oblik komuniciranja uključuje interaktivno slušanje, javne rasprave i debate. Ekološkom komunikacijom se, s obzirom na to da ona naglašava povezanost ljudi i životne sredine, u velikoj meri podiže nivo ekološke pismenosti i podstiče delovanje u skladu s principima održivog razvoja (Zikargae,
2018). Ekološka komunikacija je višedimenzionalan fenomen budući da se pod njom podrazumeva socijalna i simbolička konstrukcija životne sredine, učešće javnosti u procesu donošenja odluka od značaja za rešavanje ekoloških problema, razrešavanje konflikata, ekološko novinarstvo, uključenost društvenih medija, kampanje ekoloških udruženja, komuniciranje naučnih saznanja, pokreti ekološke pravde i za smanjenje štetnih efekata globalnih klimatskih promena, komuniciranje rizika, tzv. zeleni marketing i kampanje korporacija (Cox, 2013). „Ekološki komunikatori", kako smatraju Dej i Monro, kreiraju strategije kako bi doprli do određenih javnosti, oblikuju poruke i biraju odgovarajuće kanale kojim se obaćaju tim javnostima ili interesnim grupama (Day \& Monroe, 2020: 4). Pomenuti autori ekološku komunikaciju sagledavaju kao jedan od četiri oblika „zelene komunikacije" (GreenCOM) između različitih stejkholdera. Između ekološke komunikacije i ostala tri oblika zelene komunikacije - socijalnog marketinga, ekološkog obrazovanja i participacije javnosti - uspostavlja se odnos komplementarnosti (Day \& Monroe, 2020). Moguće je takođe praviti razliku između interne i eksterne ekološke komunikacije (SER, 2005). Prva perspektiva se uglavnom odnosi na aktivnosti poput ekološkog obrazovanja, aktivnosti na jačanju ekološke svesti (preko učešća pojedinaca u različitim aktivnostima; na primer, seminarima) do deljenja informacija o životnoj sredini. Eksterna komunikacija, $s$ druge strane, usmerena je prema dubljem sagledavanju interesa različitih stejkholdera, te, $u$ tom smislu, spektar komunikacionih aktivnosti čini dostavljanje pouzdanih informacija različitim javnostima, ekološki odnosi s javnošću, podsticanje dijaloga u zajednici, razvijanje dijaloga između stejkholdera i sl. Masovni mediji (štampa, radio i televizija) u tom smislu imaju važnu ulogu budući da podstiču „širenje (diseminaciju) informacija, difuziju inovacija i postavljaju agendu budućeg razvoja" (Tadesse, 2015: 4).

Mediji, kao „ugaoni kamen” kreiranja javnog mnjenja u savremenom društvu, ili tzv. društvuznanja, deluju kao katalizatori promena i u oblasti zaštite životne sredine (Kaul, 2017). Time se još više naglašava isprepletanost društva i medija. $U$ savremenim „informativno-intenzivnim” društvima predstave realnosti u medijima i društvenim mrežama nalaze se u središtu „deljenja znanja, difuzije novih ideja i mobilizacije delovanja", odnosno, one su značajne kako za demokratske tako i nedemokratske režime kao izvori ,informacija, dezinformacija ili zloupotrebe" (Lyytimäki et al., 2020: 2). Mediji su takođe „primarni” izvori informacija o zagađenosti vazduha i merema za smanjenja posledica ovog problema, posebno u oblastima koje su izloženije ovom zagađenju (Ramondt \& Ramírez, 2020; Mello, 2015). 
Štampa kao komunikaciono sredstvo predstavlja značajan kanal za prenos informacija od vlade, odnosno institucija država, do javnosti. Ovaj najstariji masovni medij, uprkos tome šta ne kreira događaje, pruža informacije zainteresovanim čitaocima što omogućava njihovo neposredno učešće u organizaciji različitih okupljanja - akcija, skupova, rasprava, protesta i sl. Moć štampe, a posebno uticajnih dnevnih listova, ogleda se u uvođenju inovativnih ideja u javni diskurs i pobuđivanju pažnje čitalaca za goruća pitanja današnjice. Dnevna štampa, pored toga što presudno utiče na kreiranje javnog mnjenja, nudi, po pravilu, mnogo veći prostor u odnosu na ostale masovne medije za sučeljavanje različitih stanovišta. $\mathrm{Na}$ osnovu novinskih napisa oblikuju se percepcije javnosti o merama sprovođenja ekološke politika različitih nivoa vlasti (Boyagoda, 2017). Značaj dnevne štampe još je veći u vreme pojave tzv. ekoloških katastrofa, ili incidenata, kada je neophodno javnost pravovremeno upoznati s podacima koji ukazuju na stvarne razmere nekog akutnog ekološkog problema kao i merama za ublažavanje neželjenih posledica (Dinithi Jayasekara, 2015).

\section{MATERIJALI I METODE / MATERIALS AND METHODS}

U skladu s postavljenim opštim ciljem istraživanja, a to je uvid u kvalitet izveštavanja o životnoj sredini u srpskim uticajnim štampanim medijima, odabran je odgovarajući metodološki pristup. Kao osnovna metoda korišćena je kvantitativno-kvalitativna analiza sadržaja. Ova metoda je pogodna kada treba utvrditi, opisati i klasifikovati osobine neke poruke (Neuendorf, 2002; Fajgelj, 2010; Manić, 2017). Analiza sadržaja je "najrasprostranjenija” metoda za istraživanje medijske komunikacije (Malešević, 2018). Ona je, u stvari, „sistematsko prebrojavanje, procenjivanje, interpretiranje i analiza materijalnih formi komunikacije između pojedinaca ili grupa (Bešić, 2012: 118).

Analiza sadržaja, kao i sve druge metode, mora da zadovolji osnovne kriterijume naučnog saznanja (pouzdanost i validnost), te se realizuje preko niza konsekutivnih koraka. Metodu uglavnom čine pet koraka: (1) formulisanje istraživačkih pitanja; (2) teorijska konceptualizacija i operacionalizacija koja omogućava prevođenje karakteristika teksta u opšte kategorije; (3) određivanje kriterijuma za odabir medijskih sadržaja; (4) kodiranje; te (5) analiza (procena) rezultata.

Uzorak u ovom istraživanju se sastoji od 162 teksta o životnoj sredini, koji su objavljeni u dnevnim listovima Politika, Danas, Večernje novosti i Kurir. Politika i Danas predstavljaju primere tzv. ozbiljne dnevne štampe, dok Večernje novosti i Kurir imaju polutabloidni i tabloidni karakter, redom. Ovakav izbor obezbeđuje reprezentativnost istraživanja budući da se ova četiri lista razlikuju po mnogim osobinama: vlasništvu, uređivačkoj politici, tiražu, medijskom formatu, profesionalnim i etičkim standardima, te razumevanju društvene uloge koju imaju (Torlak, 2011: 46).

Jedinicu analize predstavlja svaki objavljen tekst ekološke tematike. $U$ istraživanju je korišćen kodni list, pripremljen u skladu s postavljenim ciljevima. Prvi deo kodnog lista odnosio se na utvrđivanje formalnih karakteristika novinskog teksta; na primer, datum objavljivanja, naziv lista, naslov, novinarski žanr, veličina, autorstvo, pozicija (naslovna, unutrašnje strane), opremljenost fotografijom, grafikonom ili tabelom i sl. Razvrstavanje tektstova u smislu pripadnosti određenom novinarskom žanru obavljena je prema klasifikaciji koja identifikuje: (1) informativne (faktografske) vrste (vest i izveštaj); (2) interpretativne (proširena vest i izveštaj, komentar, osvrt, crtica i sl.); (3) analitičke (komentar, intervju, kolumna); te (4) beletrističke (priča) (Tomić, 2012: 44-45).

Namena druge celine kodnog lista je razvrstavanje tekstova po tematskoj raznovrsnosti. Određene su u tom smislu četiri opšte kategorije: (1) zagađenje životne sredine i ekološki menadžment, (2) zaštita ekoloških i prirodnih resursa, (3) biodiverztet i (4) klimatske promene. Svaka od četiri opšte kategorije je dalje raščlanjena; na primer, u okviru prve kategorije odvajani su tekstovi o zagađenosti posebno, vazduha, vode, zemljišta itd. Poslednji deo kodnog lista odnosio se na način predstavljanja ekoloških tema.

\section{REZULTATI I DISKUSIJA / RESULTS AND DISCUSSION}

U sva četiri dnevna lista su u razdoblju od 18 . januara do 13. februara objavljena 162 teksta o životnoj sredini. Odabrana četiri dnevna lista dobro predstavljaju dnevnu štampu u Srbiji na čijoj teritoriji izlazi 15 dnevnih listova; 12 ih je sa nacionalnom pokrivenošću.

Medijske objave ove tematike praćene su četiri uzastopne sedmice od ponedeljka do subote budući da se u uzorku nalazi jedan list (Danas) koji ne izlazi nedeljom. Učestalost objavljivanja novinskih tekstova o životnoj sredini, za analiziranu dnevnu štampu, prikazana je u Tabeli 1. Najviše tekstova je objavljeno u Politici, nešto manje u Večernjim novostima i listu Danas, dok se na začelju nalazi Kurir sa svega 11 napisa o ekološkim pitanjima. Detaljniji uvid u podatke prikazane u tabeli 1 , uprkos relativno kratkom periodu uzorkovanja (četiri nedelje, odnosno 24 dana), otkriva da se ne menja značajnije brojnost tekstova po sedmicama. U listu Politika, recimo, ne- 
deljno izlazi od 13 do 16 tekstova, dok se na stranicama Kurira nedeljno pojavljuje od dva do četiri novinska napisa ekološke tematike.

Tabela 1. Učestalost tekstualnih jedinica o životnoj sredini u analiziranoj dnevnoj štampi

Table 1. Frequency of tehtual unitis on the environment in analized printed media

\begin{tabular}{|c|c|c|c|c|}
\hline \multirow{2}{*}{ Period } & \multicolumn{4}{|c|}{ Dnevni list } \\
\cline { 2 - 5 } & Politika & Danas & $\begin{array}{c}\text { Večernje } \\
\text { novosti }\end{array}$ & Kurir \\
\hline $18-23.1$. & 16 & 15 & 10 & 2 \\
\hline $23-31.1$. & 14 & 9 & 12 & 4 \\
\hline $1-6.2$. & 16 & 11 & 13 & 2 \\
\hline 8-13.2. & 13 & 10 & 12 & 3 \\
\hline Ukupno & 59 & 45 & 47 & 11 \\
\hline
\end{tabular}

Razvrstavanje tekstova u uzroku obavljeno je u dva koraka. Najpre su svi novinski napisi svrstani u neku od četiri opšte kategorije - naznačene u opisu metodološkog postupka - a zatim se pristupilo daljem razvrstavanju po definisanim temama za svaku opštu kategoriju ponaosob. Dobijeni rezultati pokazuju da se pažnja autora najviše usmeravala na „zagađenje životne sredine" i „zaštitu prirodnih resursa i životne sredine" (Tabela 2). Najveći broj tekstova, ukupno 110, podveden je pod ove dve kategorije: 58 i 52, redom. U listovima Politika i Danas problematika zagađenja životne sredine je najzastupljenija. Večernje novosti, s druge strane, posvetile su 21 tekst različitim pitanjima iz domena „zaštite prirodnih resursa i životne sredine”. „Biodiverzitet” je kao oblast interesovanja urednika i novinara izazvao manje pažnje. Politika je objavila 12 ovakvih tekstova, dok u listu Kurir šest napisa o biodiverzitetu čine većinu svih tekstualnih jedinica o životnoj sredini. Naposletku, svega 22 teksta odnosila su se na „klimatske promene”.

Tabela 2. Broj tekstova u okviru glavnih ekoloških tema

Table 2. Number of texts within main environmental themes

\begin{tabular}{|c|c|c|c|c|c|}
\hline \multirow[b]{2}{*}{ Tema } & \multicolumn{4}{|c|}{ Dnevni list } & \multirow[b]{2}{*}{ Ukupno } \\
\hline & Politika & Danas & $\begin{array}{c}\text { Večernje } \\
\text { novosti }\end{array}$ & Kurir & \\
\hline $\begin{array}{l}\text { Zagađenje } \\
\text { životne } \\
\text { sredine }\end{array}$ & 24 & 15 & 17 & 2 & 58 \\
\hline $\begin{array}{l}\text { Zaštita priro- } \\
\text { de i životne } \\
\text { sredine }\end{array}$ & 15 & 14 & 21 & 2 & 52 \\
\hline Biodiverzitet & 12 & 7 & 5 & 6 & 30 \\
\hline $\begin{array}{l}\text { Klimatske } \\
\text { promene }\end{array}$ & 8 & 9 & 4 & 1 & 22 \\
\hline
\end{tabular}

Najveća tematska raznovrsnost objavljenih tekstova je primećena u okviru prve opšte kategorije - „zagađenja životne sredine” (Tabela 3). Većinu od ukupno 58 tekstova činili su oni u kojima su obrađivani različiti aspekti vezani za tri teme: (1) „politika, standardi, pravilnici u zaštiti životne sredine" (12 napisa); (2) „upravljanje vodnim resursima i vodosnabdevanje” (11); te (3) „zagađenje vazduha” (9). Izražena učestalost objava u analiziranoj dnevnoj štampi o ovim temama u skladu je sa dominantnim javnim diskursom o životnoj sredini u Republici Srbiji. Zagađenje vazduha se već u novembru 2019. godine nametnulo kao najveći ekološki problem kada su stanovnici velikih gradova (najviše u Beogradu) bili izloženi uvećanim koncentracijama štetnih gasova i čestica $u$ ambijentalnom vazduhu zbog delovanja različitih faktora; na primer, intenziteta gradskog saobraćaja, individualnih ložišta, neuobičajenih meteoroloških uslova. Vreme pandemije je podstaklo i veću učestalost napisa o povezanosti zagađenja vazduha i različitih bolesti. Ova tematika je u analiziranim listovima, kao što je pokazano u tabeli 4 , obrađena kroz četiri teksta.

Tabela 3. Raznovrsnost obrađenih problema $u$ okviru teme o zagađenju životne sredine

Table 3. Diveristy of issues within the environmental pollution theme

\begin{tabular}{|l|c|}
\hline Problem & $\begin{array}{c}\text { Broj } \\
\text { tekstova }\end{array}$ \\
\hline $\begin{array}{l}\text { Politika i standardi u zaštiti životne } \\
\text { sredine }\end{array}$ & 12 \\
\hline $\begin{array}{l}\text { Razvoj institucija i jačanje svesti o } \\
\text { životnoj sredini i potrebi za ekološkim } \\
\text { menadžmentom }\end{array}$ & 5 \\
\hline Upravljanje i odgovori na ekološke krize & 3 \\
\hline Zagađenje vodnih resursa & 3 \\
\hline Zagađenje vazduha & 9 \\
\hline Zagađenje zemljišta & 2 \\
\hline Komunalni otpad i deponije & 5 \\
\hline $\begin{array}{l}\text { Upravljanje vodnim resursima i } \\
\text { vodosnabdevanje }\end{array}$ & 11 \\
\hline Zagađenje vazduha i zdravlje ljudi & 4 \\
\hline $\begin{array}{l}\text { Projekti u cilju smanjenja zagađenja } \\
\text { životne sredine }\end{array}$ & 4 \\
\hline
\end{tabular}

Tematska raznovrsnost objavljenih tekstova u okviru druge opšte kategorije - „zaštita prirodnih resursa i životne sredine" - nešto je manja u poređenju sa „zagađenjem životne sredine”. To se može uočiti na osnovu podataka prikazanih u tabeli. 4. Skoro trećinu od 52 napisa predstavljaju oni koji se bave realizacijom različitih programa (aktivnosti) na zaštiti i unapređenju stanja životne sredine i prirodnih resursa (industrijske i urbane zone, ruralne oblasti, rečni baseni, priobalja reka, močvare, te prirodne i kulturne vrednosti). Vidno su zastupljene, sa po 14 tekstova, još dve teme: „politika, propisi i instrumenti ekološkog menadžmenta u zaštiti životne sredine" $\mathrm{i}$, degradacija 
prirodnih resursa i životne sredine (šume, zemljište, podzemne i površinske vode, priobalje reka, močvare itd)".

\section{Tabela 4. Raznovrsnost obrađenih problema $u$ okviru teme o zaštiti prirodnih resursa i životne sredine}

Table 4. Diversity of issues within the environmental protection theme

\begin{tabular}{|l|c|}
\hline \multicolumn{1}{|c|}{ Problem } & $\begin{array}{c}\text { Broj } \\
\text { tekstova }\end{array}$ \\
\hline $\begin{array}{l}\text { Politika, programi i instrumenti ekološkog } \\
\text { menadžmenta }\end{array}$ & 14 \\
\hline $\begin{array}{l}\text { Jačanje institucionalnog okvira i svesti o } \\
\text { neophodnosti zaštite životne sredine }\end{array}$ & 4 \\
\hline $\begin{array}{l}\text { Degradacija prirodnih resursa i životne sre- } \\
\text { dine (šume, zemljište, vode, močvare...) }\end{array}$ & 14 \\
\hline Tehnologije u zaštiti životne sredine & 3 \\
\hline $\begin{array}{l}\text { Zaštita i unapređenje stanja životne } \\
\text { sredine i prirodnih resursa }\end{array}$ & 17 \\
\hline
\end{tabular}

„Biodiverzitet” kao treću opštu kategoriju karakteriše manja brojnost tekstova i slabo izražena tematska raznolikost. Biološka raznovrsnost je uglavnom sagledana sa stanovišta konzervacije prirodnih predela i ekosistema, sa pripadajućom florom i faunom (ukupno 18 napisa). Najčešće je pri tome korišćena vest, u kombinaciji sa fotografijom (tzv. foto-vest), kao osnovni, faktografski novinarski žanr. Teme o „zaštiti i unapređivanju prirodnih resursa (nacionalni parkovi, vodni slivovi i specifični ekosistemi)" i ,razvijanju svesti i proširenju površina pod vegetacijom" (najviše u gradovima), obrađene su šest, odnosno pet tekstova. Evidentiran je i jedan članak u okviru teme „projekti na unapređenju biodiverziteta".

Devet objavljenih tekstova u okviru opšte kategorije „Klimatske promene”, skoro trećina, svrstana je u okviru teme „državna politika i programi za ublažavanje posledica globalnih klimatskih promena". Druga tema po zastupljenosti odnosi se na „sagledavanje energije, obnovljivih izvora energije i energetske efikasnosti" sa stanovišta klimatskih promena (sedam napisa). Dva teksta se bave „izgradnjom institucionalnih kapaciteta i jačanje svesti i informisanosti o klimatskim promenama". Najzad, sa po jednom tekstom, u uzorku je registrovano i prisustvo preostale tri teme: „predstavljanje rezultata naučnog istraživanja klimatskih promena”; „šume i klimatske promene” i „sprečavanje rizika u prilagođavanju klimatskim promenama".

Kvantitativni deo analize sadržaja o životnoj sredini, u odabrana četiri dnevna lista, odnosio se i na utvrđivanje zastupljenosti novinarskih žanrova prilikom obrade pomenutih tema. Rezultati ovog dela istraživanja su prikazani u tabeli 5 . Više od polovine tekstova (96) je napisano u formi članka. Ovaj anali- tički (istraživački) žanr je najzastupljeniji u sva četiri analizirana lista; najviše u Politici. Mnogi članci su kombinovani s nekim od ilustrativnih žanrova; najčešće s fotografijama i ilustracijama u vidu mapa, grafikona i tabela. Upadljivo je, s druge strane, da intervju nije uopšte korišćen tokom ispitivanog perioda $s$ obzirom na mogućnosti ovog analitičkog žanra.

\section{Tabela 5. Različiti novinarski žanrovi u analiziranim tekstovima}

Table 5. Various journalist genres in analized texts

\begin{tabular}{|l|c|c|c|c|c|}
\hline $\begin{array}{c}\text { Novinarski } \\
\text { žanr }\end{array}$ & \multicolumn{4}{|c|}{ Dnevni list } & \multirow{2}{*}{$\begin{array}{c}\text { Broj } \\
\text { tekstova }\end{array}$} \\
\cline { 2 - 5 } & Politika & Danas & $\begin{array}{c}\text { Večernje } \\
\text { novosti }\end{array}$ & Kurir & \\
\hline Vest & 6 & 8 & 18 & & 32 \\
\hline Izveštaj & 7 & 5 & & 4 & 16 \\
\hline Komentar & 2 & 4 & & & 6 \\
\hline Beleška & 1 & 2 & & & 3 \\
\hline Crtica & & & 1 & & 1 \\
\hline Osvrt & 3 & 4 & & & 7 \\
\hline Članak & 40 & 21 & 28 & 7 & 96 \\
\hline Esej & & 1 & & & 1 \\
\hline
\end{tabular}

Faktografski oblici - vest i izveštaj - zastupljeni su sa po 32 i 16 tekstova, redom. Većina vesti je takođe kombinovana sa fotografijom (naročito u Večernjim novostima). Znatno manje su korišćeni interpretativni žanrovi (komentar, beleška, crtica i osvrt) u obradi ekoloških tema. U uzorku je naposletku mesto našao $i$ jedan esej - jedna od formi beletrističkog žanra. Rezultati analize predočeni u tabeli 5 ukazuju na raznovrsnost korišćenih novinarskih žanrova (posebno u listu Danas) što je, čini se, veoma značajno kod obrade tema iz oblasti zaštite životne sredine. Kvalitetu izveštavanja o ovoj problematici u dnevnoj štampi doprinosi i velika učestalost objavljenih članaka koji budući da ovaj novinarski žanr pruža bolje mogućnosti za opisivanje višedimenzionalnih problema.

Analiza medijskih objava ukazuje i na izvesne nedostatke. Nijedna od analiziranih novina nema dnevnu rubriku posvećenu zaštiti životne sredine. Tabloid Kurir jednom nedeljno posvećuje dve strane ekološkim pitanjima u okviru rubrike "Održiva budućnost”. Svojevremeno je Politika jednom mesečno, do kraja 2009. godine, negovala rubriku „Eko oko” koja je donosila i po desetak tekstova o uspesima ali i promašajima u oblasti zaštite životne sredine.

Analiza učestalosti medijskih objava o životnoj sredini u odabranim dnevnim listovima pokazuje da ova vrsta štampe ostaje glavni izvor infrormacija iz ove oblasti. Novinski napisi često podstiču i poslenike iz elektronskih medija da obrađuju različita ekološka pitanja. Utvrđena najveća zastupljenost ekoloških sadržaja u Politici je u saglasnosti i sa prethodnim istraživanjima u različitim razdobljima (Vuković i dr., 1997; Jovanović i Aćimović, 2014). 


\section{ZAKLJUČAK / CONCLUSION}

Rezultati procene sadržaja tema iz oblasti zaštite životne sredine upućuju na opšti zaključak da se ova tematika propoznaje kao potencijalno privlačna za čitaoce sva četiri analizirana dnevna lista. U obrađenim ekološkim sadržajima, gledano prema primenjenim oblicima novinarskog izražavanja, najzastupljeniji su članci, što omogućava višedimenzionalno sagedavanje tema. Analitički i interpretativni novinarski žanrovi posebno su značajni kod obrade ekološke problematike. Prisustvo tema i stepen njihove obrade varira od lista do lista, pri čemu se, po ovom kriterijumu, izdvaja Politika. Veća šarolikost obrađenih tema na stranicama Politike može se pripisati specijalizaciji novinara za ovu specifičnu problematiku.

Dnevni listovi Politika i Danas dorpinose javnoj raspravi o različitim ekološkim poliitkama budući da je uređivačkom politikom ostavljen dodatni prostor za izražavanje mišljenja građana, odnosno predstavnika udruženja; najčešće u okviru redovnih rubrika Pogled i Među nama (u Politicl), Dijalog (u listu Danas), te povremenih dodataka. Identifikovanje slabosti u realizaciji tekućeg menadžmenta, uglavnom kroz napise eminentnih stručnjaka, vodilo je ponekad izmenama odgovarajućih javnih politika poput, recimo, mera za smanjenje zagađenja vazduha u Beogradu, početkom 2021. godine.

Uprkos izraženoj ekološkoj krizi u Srbiji, intenziviranoj ponajviše prevelikim zagađenjem vazduha (posebno u novembru 2019. godine), samo jedan od analizirana četiri dnevna lista (Kurir) ima posebnu stranu posvećenu zaštiti životne sredine (jednom nedeljno). Čitaoci, s obzirom na to da su ovi sadržaji rasuti na raznim stranama, mogu ostati uskraćeni za informacije uprkos zainteresovanosti. Izveštavanje o lokalnim problemima (najčešće, izvorima zagađenja) je, u odnosu na teme od nacionalnog i globalnog karaktera, najprisutnije u sva četiri analizirana dnevna lista. Pozitivnim se čini to što su štampani mediji u vreme pandemije učestalije objavljivali tekstove o povezanosti zagađenosti vazduha i različitih bolesti.

Premda se kvalitet izveštavanja o životnoj sredini u štampanim medijima u Srbiji može smatrati dobrim, trebalo bi stremiti poboljšanjima. Ona se mogu postići različitim merama. Različiti podsticaji za novinare koji se bave ovom tematikom (nagrade, učešće na seminarima i sl.) mogli bi uroditi plodom u relativno kratkom periodu. Institucije vlasti, sa svoje strane, pravovremenim organizovanjem konferencija za medije (posebno u vreme vanrednih dešavanja), dostavljanjem pouzdanih i relevantnih podataka i drugim merama, mogle bi uveliko da doprinesu kvalitetnijem ekološkom izveštavanju, sužavanjem prostora pre svega za nepoverenje $u$ javnosti povodom raznih pitanja. Vreme pandemije je samo dodatno aktueli- zovalo učešće javnosti, nezaobilazne karike ekološkog menadžmenta.

\section{Zahvalnost / Acknowledgement}

Istraživanja predstavljena u ovom radu su urađena uz finansijsku podršku Ministarstva prosvete, nauke i tehnološkog razvoja Republike Srbije, u okviru finansiranja naučno istraživačkog rada na Univerzitetu u Beogradu, Tehničkom fakultetu u Boru, prema ugovoru sa evidencionim brojem 451-039/2021-14/200131.

\section{LITERATURA / REFERENCES}

[1] Bešić, M. (2011), Metodologija političkih nauka, FPN, Podgorica.

[2] Boyagoda, E.W.M.S. (2017), Reporting green: An exploratory study of news coverage of environmental issues in Sri Lankan newspapers, Asia Pacific J. of Adv. Business and Social Studies, 3(1), 1-11.

[3] Cox, R. (2013), Environmenal communication and the public shere, Sage, Los Angeles.

[4] Day, B.A., Monroe, M.C. (2020), Environmental education and communication for a sustainable world: Handbook for international practitioners, Academy for Educational Development, Washington.

[5] Dinithi Jayasekara, A.H. (2015), Disaster reporting in print media, Int. J. of Sci. Research and Innovative Technology, 2(9), 1-5.

[6] Fajgelj, S. (2010), Metode istraživanja ponašanja, Centar za primenjenu psihologiju, Beograd.

[7] Jovanović, Đ.M., Aćimović, D.D. (2014), Pitanja životne sredine $\mathrm{i}$ dostignuti stepen medijske pokrivenosti u Republici Srbiji, Tehnika - Kvalitet IMS, standardizacija i metrologija, 14(2), 335-443.

[8] Kaul, V. (2017), The environmental crisis and the role of media, Int. J. of Trend in Scientific Research and Development, 1(4), 684-697.

[9] Lyytimäki, J., Kangas, H-L., Mervaala, E., Vikström, S. (2020), Muted by a Crisis? COVID-19 and the long-term evoluation of climate change of newspaper coverage, Sustainability, 12(8575), 1 12.

[10] Malešević, K. (2018), (Ne)odgovornost novinarskog izveštavanja o osetljivim društvenim grupama u štampanim medijima, Communication and Media, 13(42), 27-56.

[11] Manić, Ž. (2017), Analiza sadržaja u sociologiji, Čigoja, Beograd.

[12] Mello, S. (2015), Media coverage of toxic risks: A content analysis of pediatric environmental health information available to new and expected mothers, Health Commun., 30, pp. 1-11. 
[13] Neuendorf, K. (2002), The content analysis guidebook, Sage, London.

[14] Ramondt, S., Ramírez, A.S. (2020), Media reporting on air pollution: Health risk and precautionary measures in national and regional newspapers, Int. J. Environ. Res. Public Health, 17(6516), 1-10.

[15] SER (Social and Environmental Report), Toyota Indystries Corporation, 2005. http://www.toyotaindustries.com, posećeno dana 8.2.2021.

[16] Tadesse, A. (2015), The practices and challenges of environmental issues coverage in state broad cast media: Ethiopian Broadcasting Corporation $(E B C)$ in focus. MSc thesis, Addis Ababa Univ- ersity Graduate School of Journalism and Communication.

[17] Tomić, B. (2012), Uvod u medije, Čigoja.

[18] Torlak, N. (2011), Medijska slika žene u Srbiji, Communication and Media, 6(19), 39-52.

[19] Vuković, M., Vuković, M., Marjanović, T. (1997), Doprinos dnevnog lista Politika formiranju javnog mnjenja o životnoj sredini, Ecologica, 4(4), 49-52.

[20] Zikargae, M.H. (2018), Analysis of environmental communication and its implication to sustainable development in Ethiopia, Science of the Total Environment, 634, 1593-1600. 